International Journal of Engineering \& Technology, $7(3.29)(2018) 253-258$
SPC
International Journal of Engineering \& Technology
Website $: \frac{w w . s c i e n c e p u b c o . c o m / i n d e x . p h p / I J E T}{2}$
Research paper

\title{
Investigations on grid connected PV system under variable irradiation conditions
}

\author{
G. Sreenivasa Reddy ${ }^{1}$, T. Bramhananda Reddy ${ }^{2}$, M. Vijaya Kumar ${ }^{3}$ \\ ${ }^{1}$ Research Scholar, JNTUA, Anantapuramu \\ ${ }^{2}$ Professor, Dept. of EEE, G. Pulla Reddy Engineering College (Autonomous), Kurnool, AP, India \\ ${ }^{3}$ Professor, Dept. of EEE, JNTUA, Anantapuramu \\ *Corresponding author E-mail: nivasa7hills@gmail.com
}

\begin{abstract}
A solar photovoltaic panel or a solar PV module is a device, which is to be considered universality the basic constituent of a solar photovoltaic system and is a combination of series and parallel assembly of solar cells. The electrical performance of this solar photovoltaic module be contingent on different environmental situations like PV cells/module solar spectral (air mass), ambient temperature, solar irradiance, angle-of-incidence. With these dependent conditions, there will be a petite chance to operate at its maximum power point (MPP) Hence, a Perturb and Observe (P\&O) MPP algorithm is employed which draws considerable power with the desired time response. In present work, the interfacing of Solar PV system with the utility grid system which is having $15 \mathrm{~kW}$ based on the Voltage Oriented Control (VOC). The temperature of the individual photovoltaic cell and solar irradiation are to be considered as inputs for the simulation process, whereas the duty cycle of the DC-DC boost converter is an output of the P\&O controller. Performance of this grid-connected PV system with VOC method is analyzed with the simulation results and \%THD values of the voltage and current at coupling point is verified. The results show the superiority of VOC method and its high dynamic behavior under variable irradiation conditions.
\end{abstract}

Keywords: DC/DC Boost Converter; P\&O MPPT; Grid Connected PV System; VOC; VSI.

\section{Introduction}

Past few decades the fossil fuels take a vital role with his major contribution in power generation. It is always an important that energy issue for the development of country and also relation in between inter and intra countries, and present era it become priority concept because of the aware about the limitations of presenttraditional energy sources like coal and petroleum and also the negative climate impacts and demerits of using fossil fuels and it becomes insufficient to meet the gradual increase of the load demand [2]. Due to the increasing load demand and lack of resources, the future focus is towards research and development of alternative energy sources, in order to survive from the energy crisis many industries and government encouraging with different attractive schemes towards the alternative energy source. With free availability of renewable energy resources it is identified that the important alternatives are air, water and solar photovoltaic

(PV). Within these three, again the solar PV is chosen as a best one irrespective of the location and nature of loads. It attains important due to a lot of research is done on PV system and converter technology with power semiconductor devices with reduced cost, size and increased performance [3]. But in the large-scale installation of the PV system has a major disadvantage due to its initial cost and low conversion efficiency [4]. every solar PV panel has multiple current-voltage characteristics each of the different combinations of conditions that would affect the STC such as temperature, air mass, irradiance and at every characteristic curve the maximum power point will differ and need to track this maximum PV power output [5]. The different maximum power point harvesting techniques are used to find the MPP and are listed in [6], and are shown in below fig 1 .

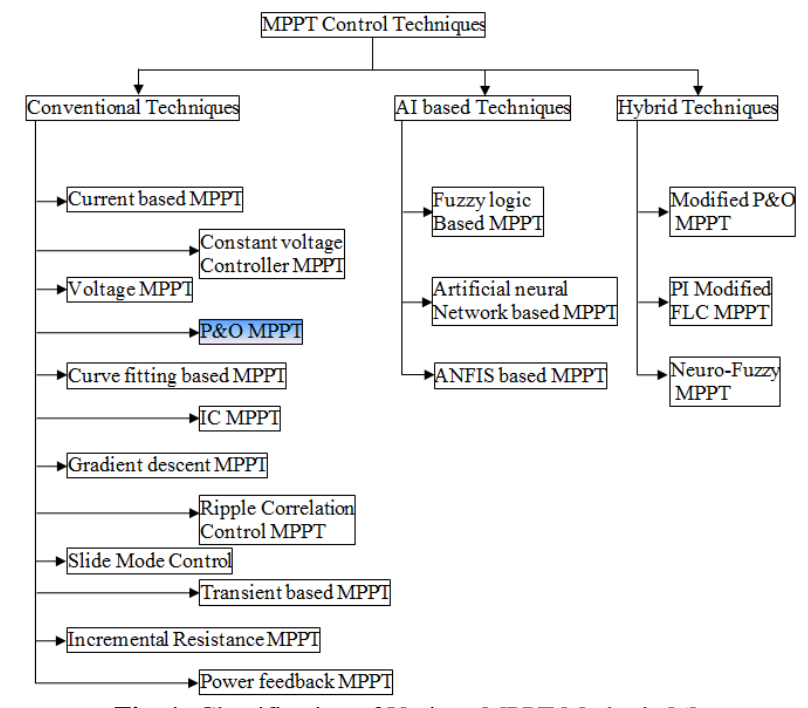

Fig. 1: Classification of Various MPPT Methods [6].

Among the above techniques, the universally accepted method of obtaining MPP is the Perturb and Observer (P \& O) [7-10]. In present paper pays under all the possible conditions the conventional $\mathrm{P} \& \mathrm{O}$ method tracks the maximum power irrespective of the system operating conditions. Along with the $\mathrm{P} \& \mathrm{O}$, the VOC based control technique is employed for the enhancement of the efficiency of 
grid-connected solar PV system. In this present work, it is divided into five different sections, description about the grid-connected PV system by section II, whereas section III will be the complete characteristics and the sizing of the PV array which is considered is given, and the clear explanation of MPPT based P\&O algorithm are in section IV, and the results are given in section V, finally the conclusion will summarizes a idea of the present work.

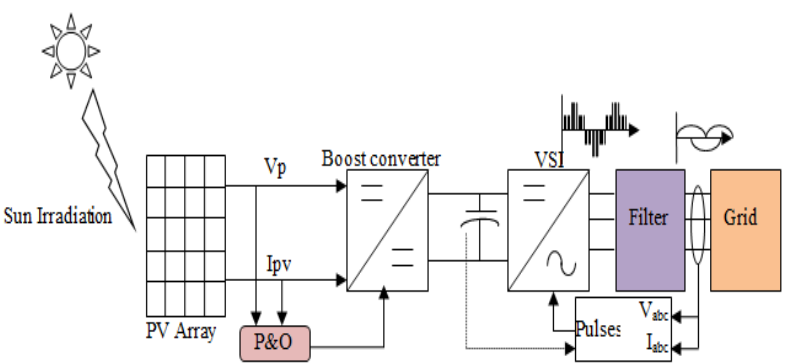

Fig. 2: Representasion Diagram of Grid Connected VOC Based PV System.

\section{System description}

At standard test conditions (STC) the PV array in the proposed paper generates a maximum power of $15 \mathrm{~kW}$.Each module of $305 \mathrm{~W}$ is employed for the creation of the array. Each module contains 96 cells. These modules are arranged in such a manner that a total of $15 \mathrm{~kW}$ energy is generated from the solar irradiation. A total of 5 series and 10 parallel modules are connected $(5 * 10 * 305=15250 \mathrm{~W} \approx 15 \mathrm{~kW})$. The detailed specifications of the solar PV module which is selected are mentioned in Table.1. From the schematic diagram (Fig 2) representation, the first block PV array has only one input that allows unpredictable (continuous changing) sun irradiance (in $\mathrm{W} / \mathrm{m}^{2}$ ) and temperature $\left({ }^{\circ} \mathrm{C}\right.$ ) is chosen as constant. For the simulation process, the irradiance profile is defined by a Signal Builder block as input for the PV array.The current-voltage and Power - voltage characteristics of the single module with below specifications mentioned in table 1 are shown in Fig. 3 , and the I-V and P-V characteristics of a total array are shown in Fig. 4.

Table 1: Specifications of the Solar Module

\begin{tabular}{|c|c|}
\hline Total number of solar cells in Panel/module & 96 \\
\hline Open Circuit Voltage (in Volts) $\left(\mathrm{V}_{\mathrm{oc}}\right)$ & 64.20 \\
\hline Short Circuit Current (in Amps) $\left(I_{\mathrm{sc}}\right)$ & 5.96 \\
\hline Voltage at MPP (in Volts) ( $\left.\mathrm{V}_{\mathrm{MPP}}\right)$ & 54.70 \\
\hline Current at MPP (in Amps) ( $\left.\mathrm{I}_{\mathrm{MPP}}\right)$ & 5.58 \\
\hline Power at MPP (in Watts) $\left(\mathrm{P}_{\mathrm{MPP}}\right)$ & 305.226 \\
\hline
\end{tabular}
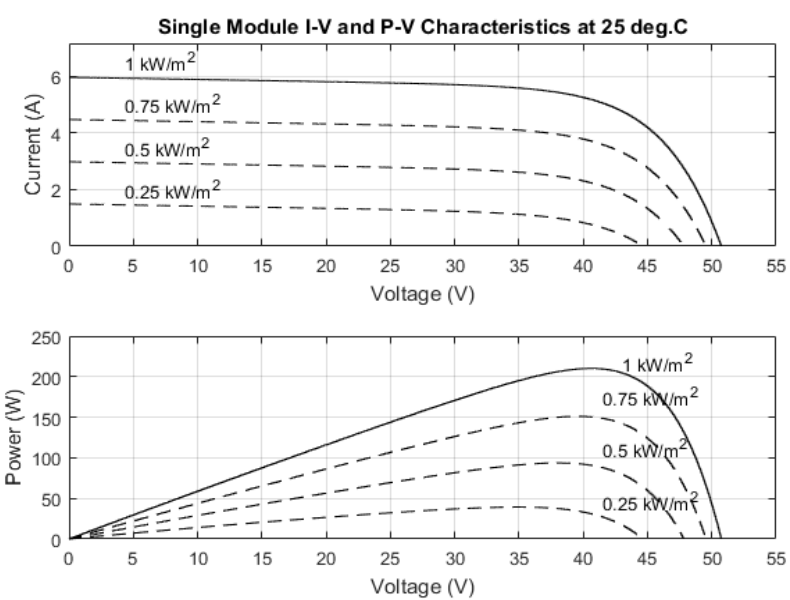

Fig. 3: P-V and I-V Characteristics of Single Module at Constant Temperature $25 \mathrm{oC}$ and Varying Irradiance.
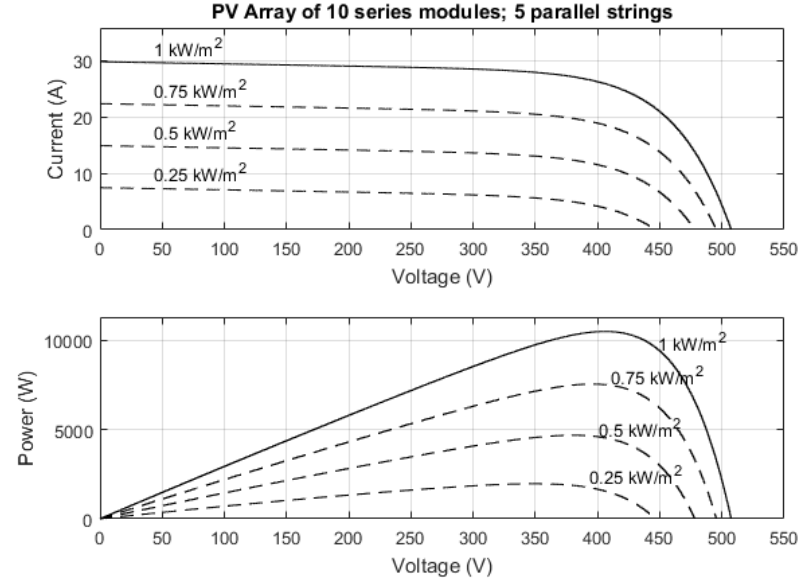

Fig. 4: P-V and I-V Characteristics of Complete Array at Constant Temperature $25 \mathrm{oC}$ and Varying Irradiance.

\section{MPPT control strategy}

The $\mathrm{P} \& \mathrm{O}$ algorithm which is employed in [5] is used here for the generation of the pulses for the boost converter. The Fig 5.shows the flowchart of the $\mathrm{P} \& \mathrm{O}$ algorithm. The irradiance, duty cycle generated from the algorithm is shown in Fig.6. , in Fig 6.it can be observed that the duty cycle is controlled with the output of the voltage and currents of the PV array. The top trace in Fig 6.is the irradiance value and the bottom trace is generated duty cycle for the boost converter (DC-DC).

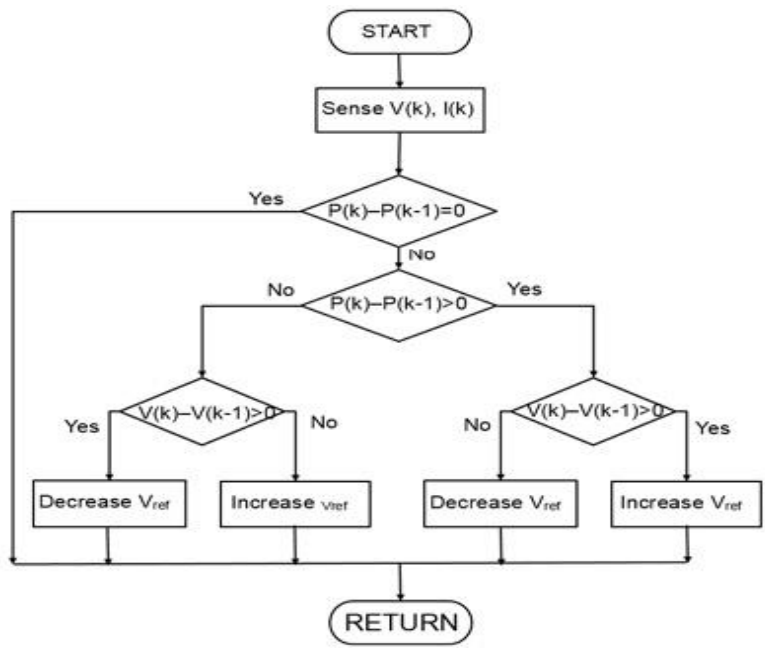

Fig. 5: Flowchart of the $\mathrm{P} \& \mathrm{O}$ Algorithm.
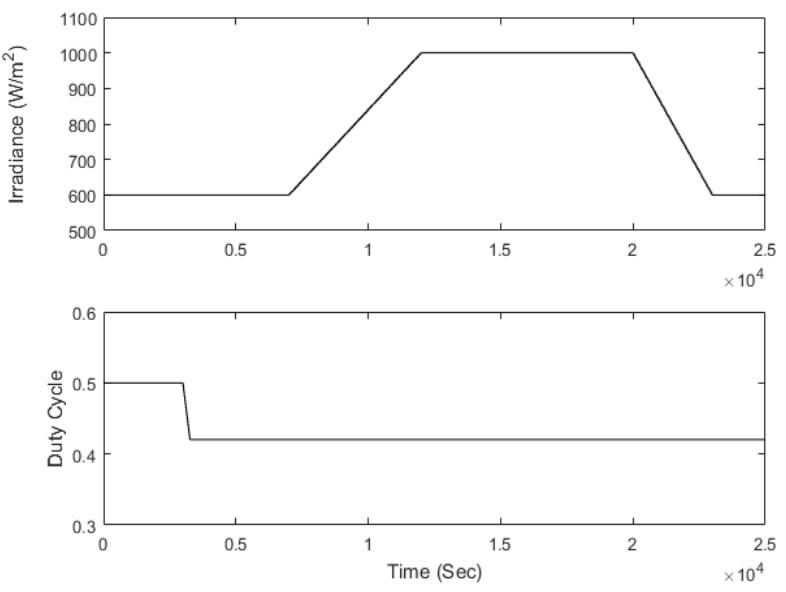

Fig. 6: Variation of Duty Cycle Based on the Irradiation. Top Trace: Irradiation of Sun in W/M2. Bottom Trace: Duty Cycle. 


\section{Discussion and simulation results}

The grid-connected PV system is employed beneath both fast and slow alteration of environmental situations (variable irradiance) with the constant ambient temperature is maintained, this can be observed in the top trace of the Fig.6. The results of the grid-connected PV system are explained in three different stages. In the first stage, the irradiation is increased from minimum to maximum. The results for this stage are shown in Fig 7. The top trace shows the irradiation it is increased from $600 \mathrm{~W} / \mathrm{m} 2$ to $1000 \mathrm{~W} / \mathrm{m} 2$. During this time the PV array voltage, current and power are shown in Fig 7. whereas in Fig 8. in the top trace, it is observed that a constant value of the DC voltage is obtained from the DC-DC converter and is fed to the voltage source inverter for the conversion of the DC into AC. A two-level voltage waveform can be observed in the second trace in Fig.8. The three phase voltage, current waveforms for feeding into the grid is shown in Fig 9. During the grid fed inversion it is required to maintain near to unity power factor this can be seen in Fig 10. i.e., the voltage and current both in the same phase only. The active and reactive powers fed to the grid are also shown in Fig 11. All these results are shown for the non-uniform incremental irradiation values.
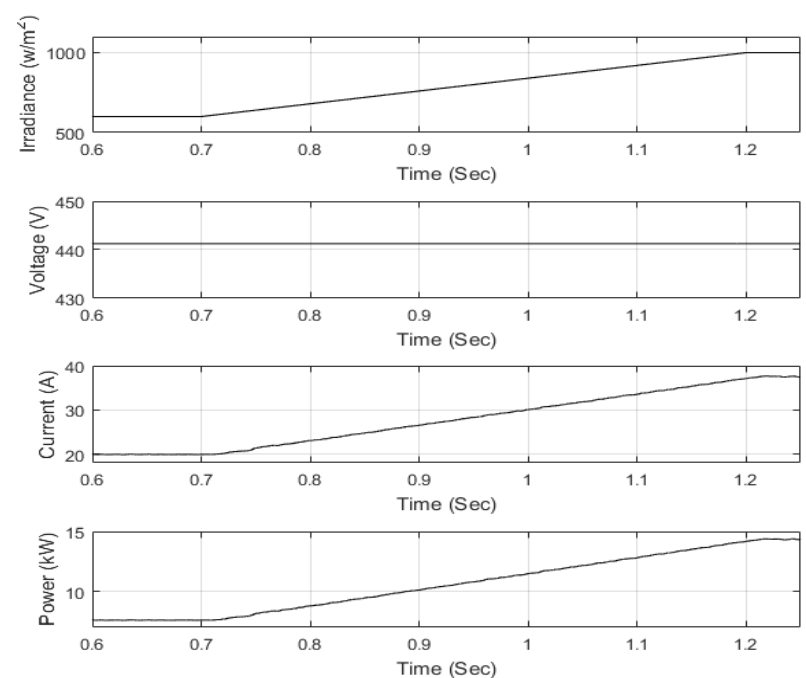

Fig. 7: Irradiance, PV Array Voltage, Current and Power Variations during the Irradiation Is Changed from 600W/M2 to $1000 \mathrm{~W} / \mathrm{M} 2$
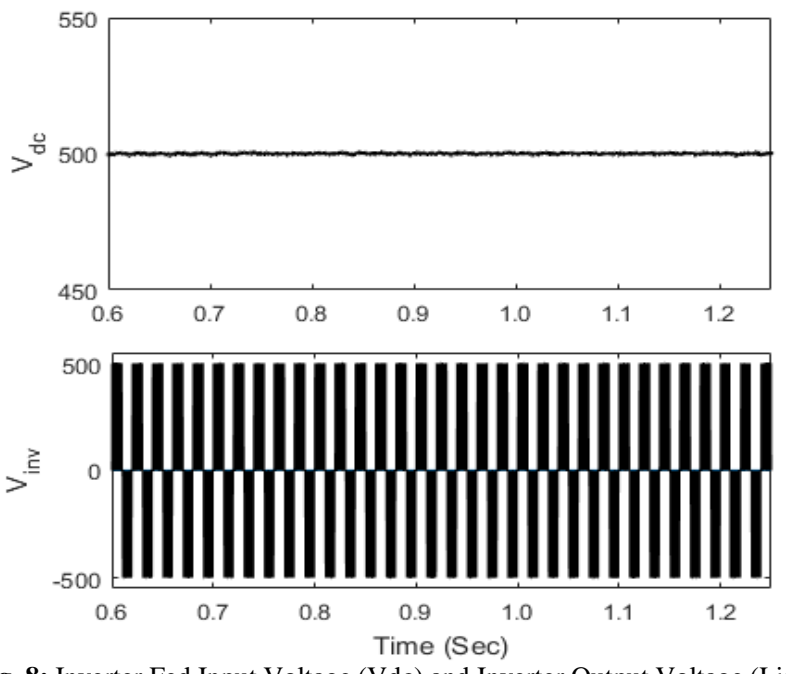

Fig. 8: Inverter Fed Input Voltage (Vdc) and Inverter Output Voltage (Line to Line) During the Irradiation Is Changed from 600W/M2 to 1000 W/M2.
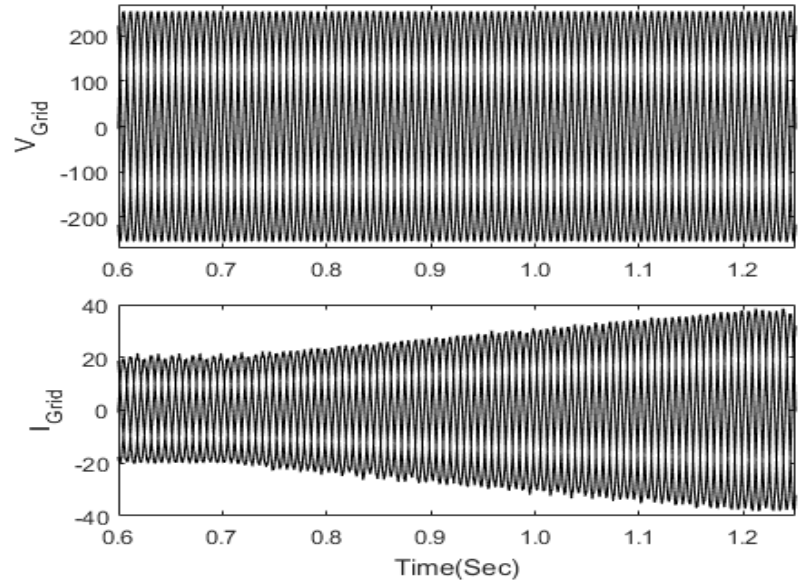

Fig. 9: Variation in Grid Fed Voltages and Currents during the Irradiation Is Changed from 600W/M2 to $1000 \mathrm{~W} / \mathrm{M} 2$.
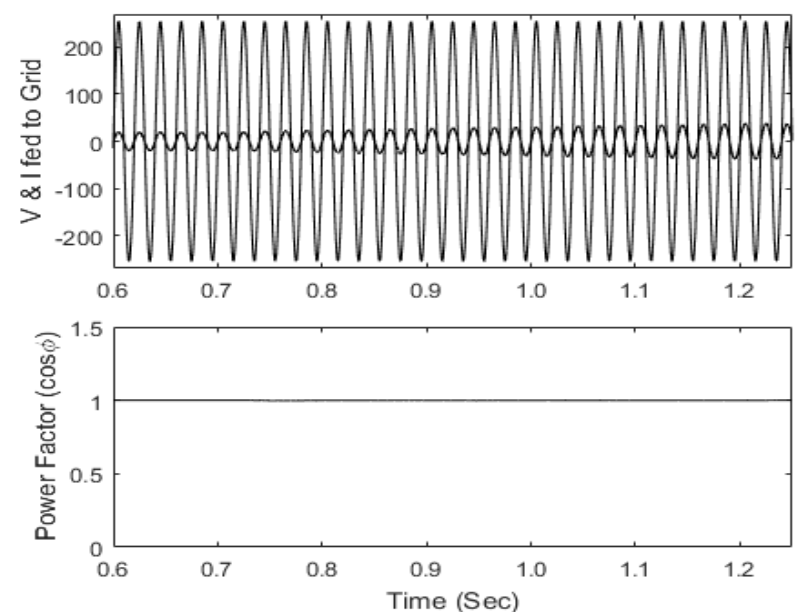

Fig. 10: Phase Sequence and Power Factor of Grid Fed Voltage and Currents during the Irradiation Is Changed from $600 \mathrm{~W} / \mathrm{M}^{2}$ to $1000 \mathrm{~W} / \mathrm{M}^{2}$.
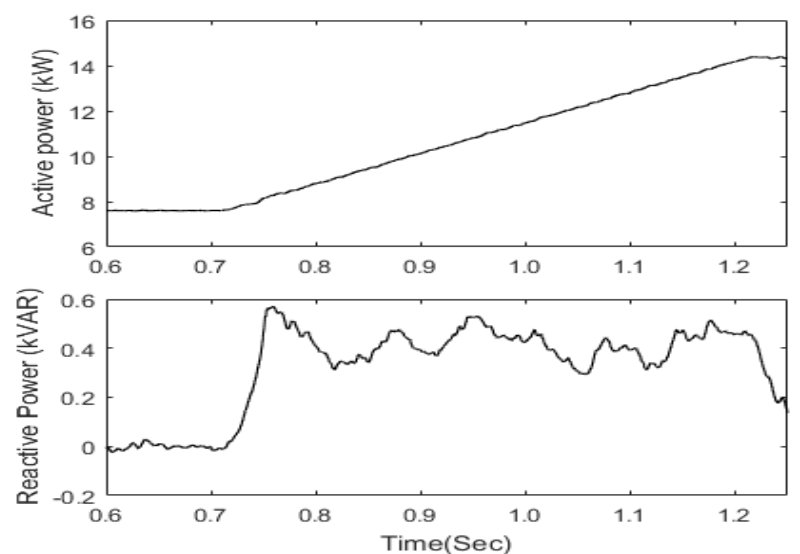

Fig. 11: Grid Fed Active Power (In Kw) and Reactive Power (Inkvar) During the Irradiation Is Changed from $600 \mathrm{~W} / \mathrm{M}^{2}$ to $1000 \mathrm{~W} / \mathrm{M}^{2}$.

In the second stage, the irradiation is maintained constant. The results for this stage are shown in Fig 12. The top trace shows the irradiation it is maintained at $1000 \mathrm{~W} / \mathrm{m} 2$. During this time the PV array voltage and currents are presented in Fig 12. In Fig 13, the top trace is identified that a constant value of the DC voltage is obtained from the DC-DC converter and is fed to voltage source inverter for the conversion of the DC into AC. A two-level voltage waveform can be observed in the second trace in Fig 13. In Fig 14. The grid fed three-phase voltage and currents can be seen. During the grid fed inversion it is required maintain the unity power factor this can be seen in Fig 15. i.e., the voltage, current both are in the same phase only. The active and reactive powers fed to the grid are also shown in the Fig.16. All these results are shown for the constant irradiation values. 

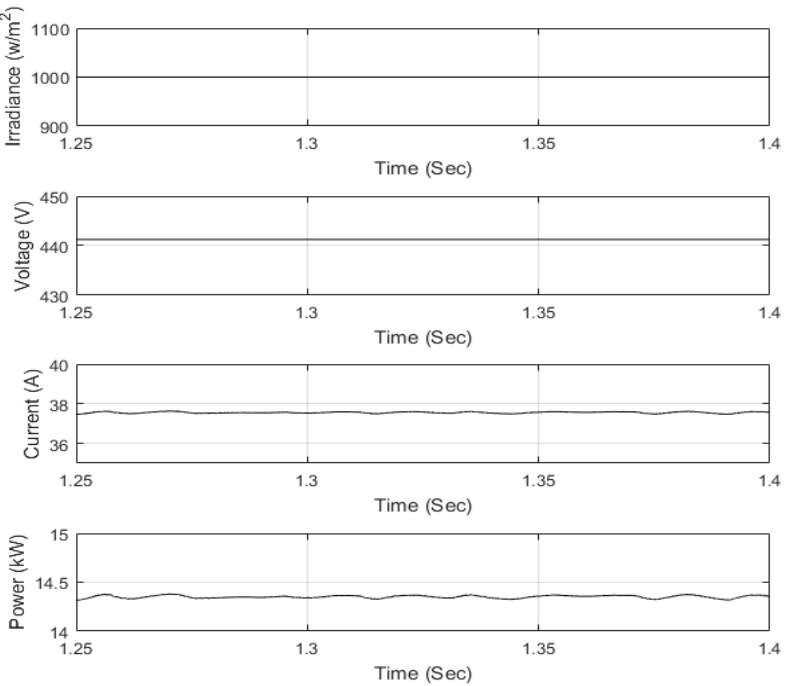

Fig. 12: Irradiance, PV Array Voltage, Current and Power Variations during the Irradiation Is Constant at $1000 \mathrm{~W} / \mathrm{M}^{2}$.
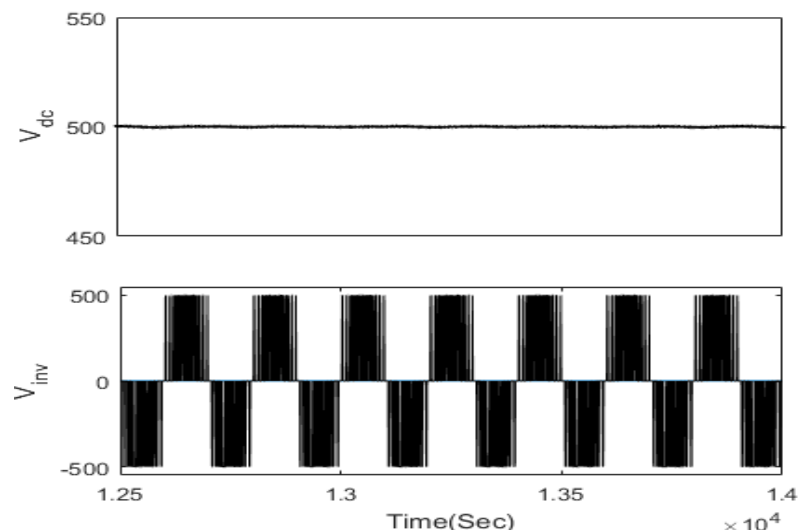

Fig. 13: Inverter Fed Input Voltage (Vdc) And Inverter Output Voltage (Line to Line) during the Irradiation Is Constant at $1000 \mathrm{~W} / \mathrm{M}^{2}$.
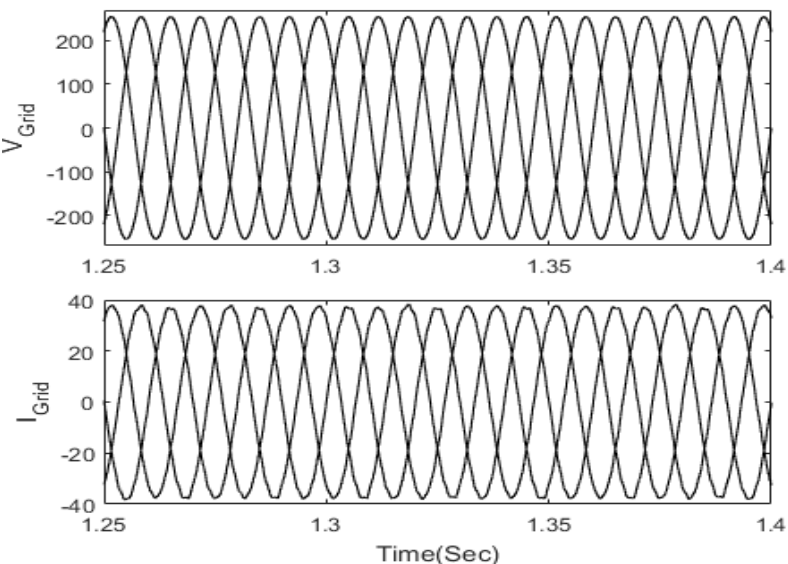

Fig. 14: Variation in Grid Fed Voltages and Currents during the Irradiation Is Constant at $1000 \mathrm{~W} / \mathrm{M}^{2}$.
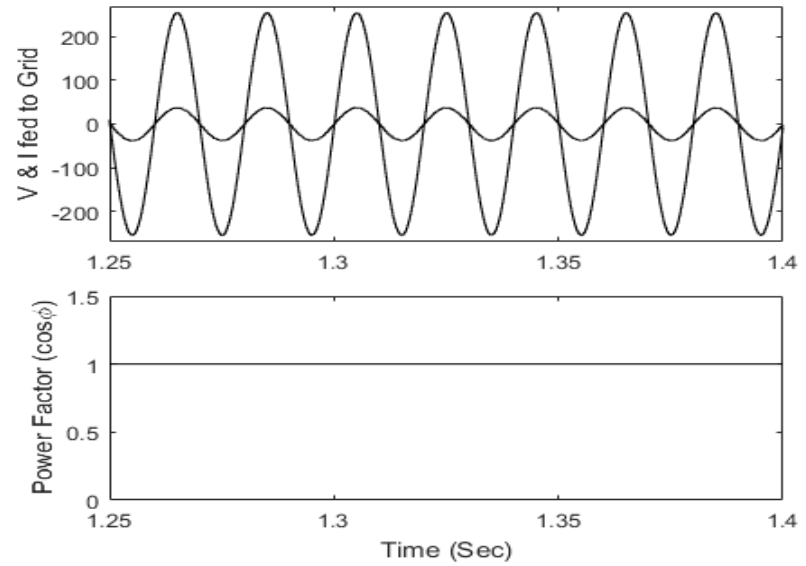

Fig. 15: Phase Sequence and Power Factor of Grid Fed Voltage and Currents during the Irradiation Is Constant at $1000 \mathrm{~W} / \mathrm{M}^{2}$.
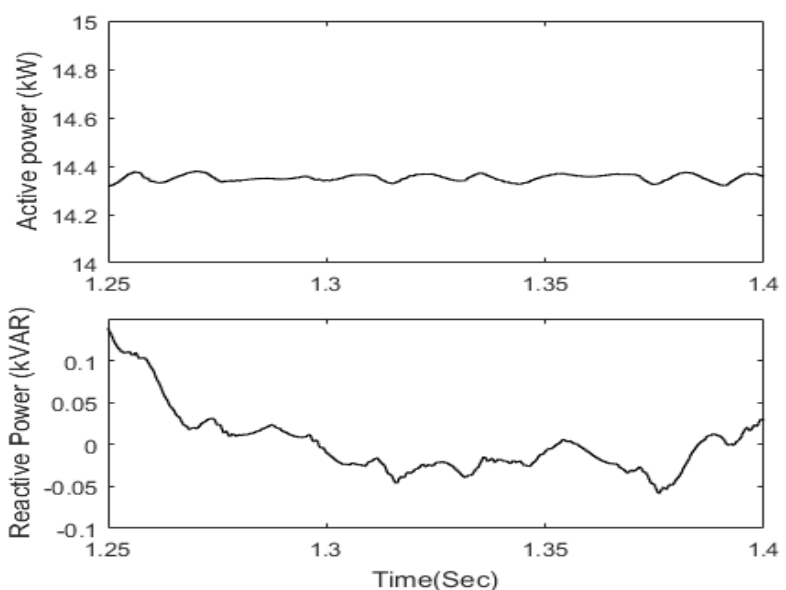

Fig. 16: Grid Fed Active Power (In Kw) and Reactive Power (Inkvar) during the Irradiation Is Constant at $1000 \mathrm{~W} / \mathrm{M}^{2}$.

In third stage, the irradiation is decreased from maximum to minimum. The results for this stage are shown in Fig 17. The top trace shows the irradiation it is increased from $1000 \mathrm{~W} / \mathrm{m} 2$ to $600 \mathrm{~W} / \mathrm{m} 2$. During this time the PV array voltage and currents are presented in Fig 17. In Fig 18., the top trace it is observed that a constant value of the DC voltage is obtained from the DC-DC converter and is fed to the voltage source inverter for the conversion of the DC into AC. A two-level voltage waveform can be observed in the second trace in Fig 18. In Fig 19. The grid fed three-phase voltage and currents can be seen. During the grid fed inversion it is required to maintain near to unity power factor this can be seen in Fig 20. i.e., the voltage and current both in the same phase only. The active and reactive powers fed to grid are also shown in Fig 21. All these results are shown for the non-uniform incremental irradiation values. 

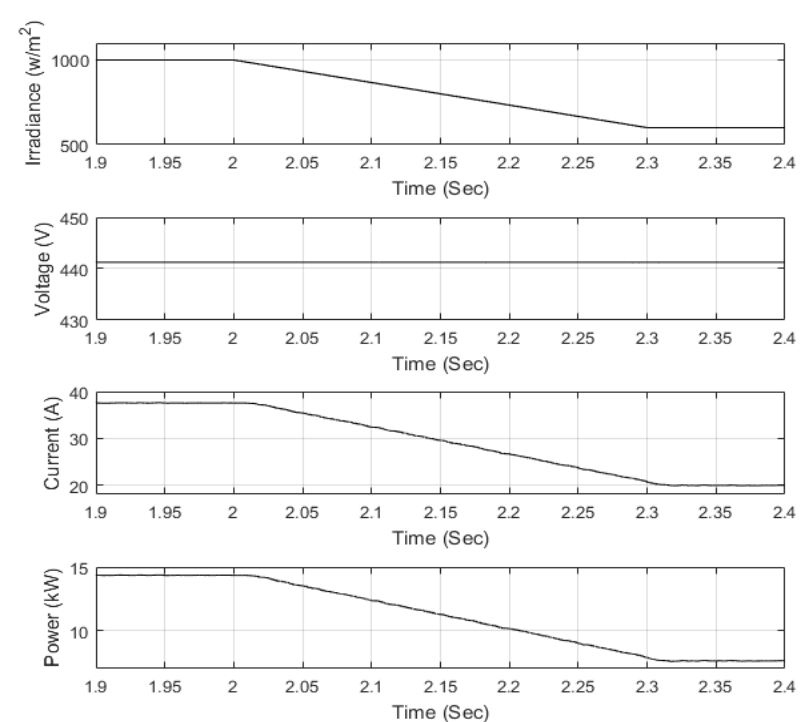

Fig. 17: Irradiance, PV Array Voltage, Current and Power Variations during the Irradiation Is Changed from $1000 \mathrm{~W} / \mathrm{M}^{2}$ to $600 \mathrm{~W} / \mathrm{M}^{2}$.
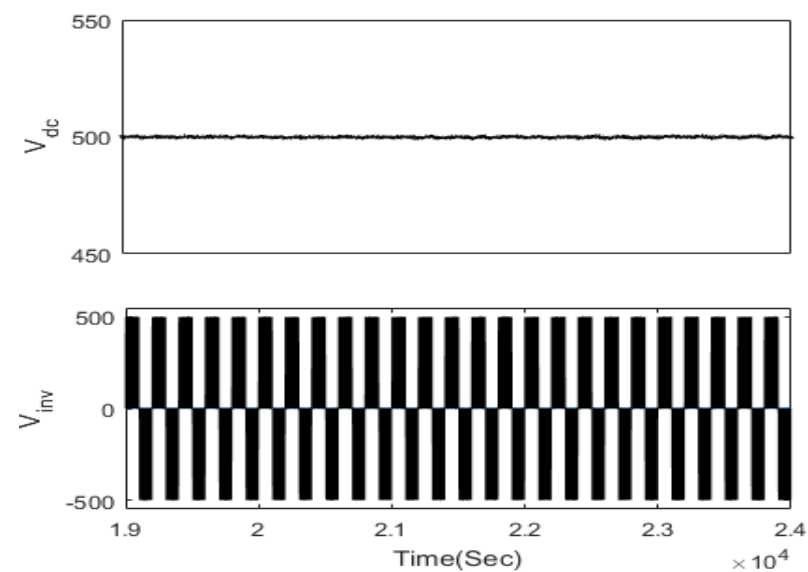

Fig. 18: Inverter Fed Input Voltage (Vdc) and Inverter Output Voltage (Line to Line) during the Irradiation Is Changed from $1000 \mathrm{~W} / \mathrm{M}^{2}$ to $600 \mathrm{~W} / \mathrm{M}^{2}$.
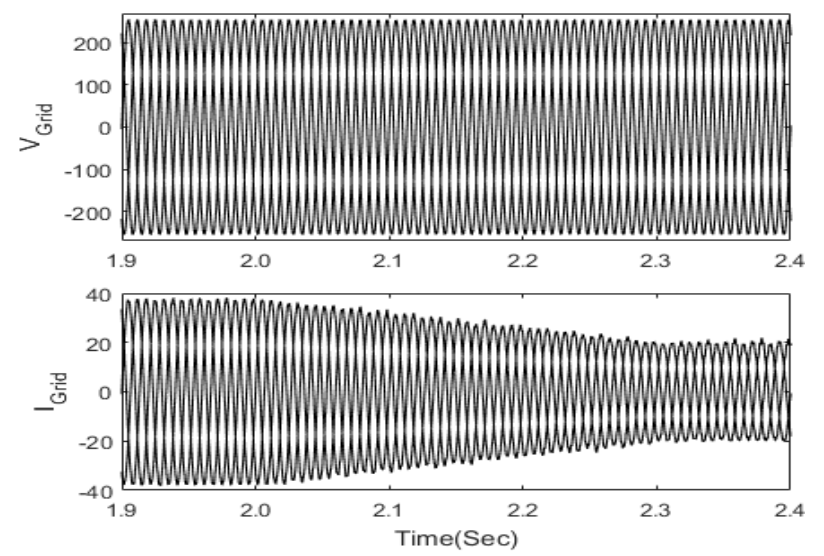

Fig. 19: Variation in Grid Fed Voltages and Currents during the Irradiation Is Changed from $1000 \mathrm{~W} / \mathrm{M}^{2}$ to $6000 \mathrm{~W} / \mathrm{M}^{2}$.
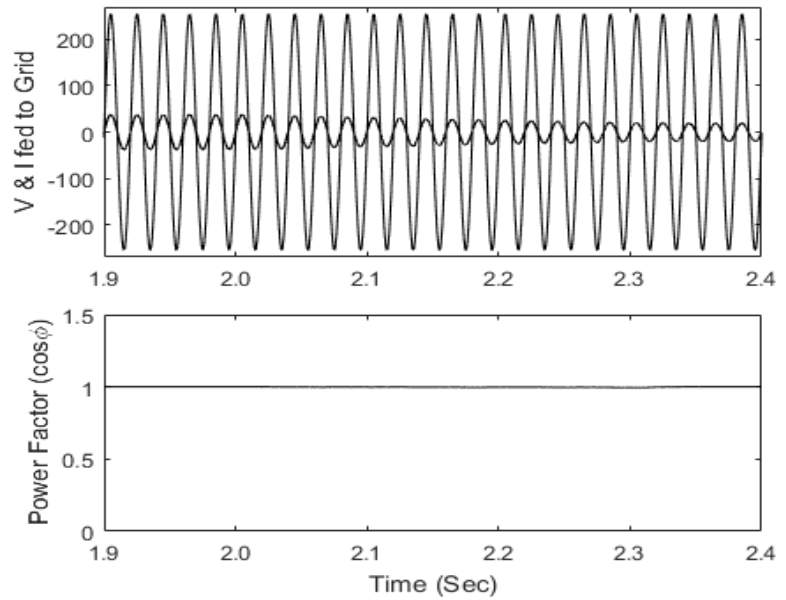

Fig. 20: Phase Sequence and Power Factor of Grid Fed Voltage and Currents during the Irradiation Is Changed from 1000W/M2 to $600 \mathrm{~W} / \mathrm{M} 2$.
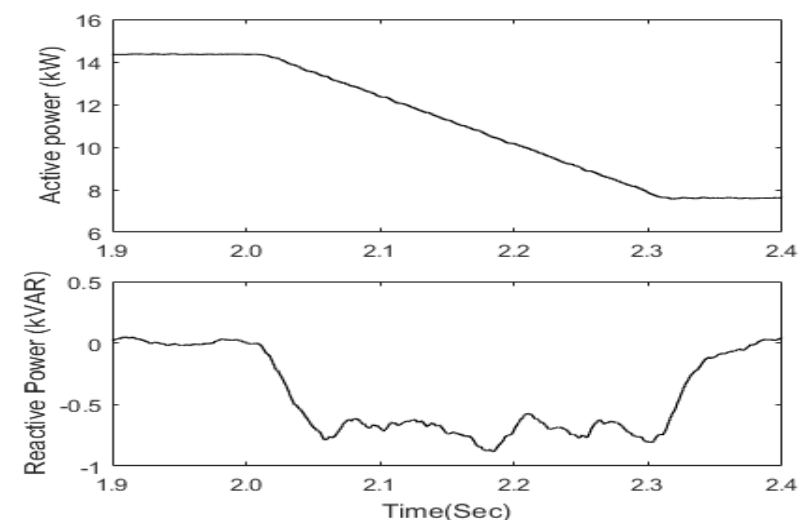

Fig. 21: Grid Fed Active Power (In Kw) and Reactive Power (Inkvar) During the Irradiation Is Changed from 1000W/M2 to $600 \mathrm{~W} / \mathrm{M}^{2}$.

The \% THD of Voltage and Currents are shown in Fig 22. and Fig 23. it is identified, the \% THD of the voltage waveform is very low and there is a little amount of THD is present in the current fed to the grid.

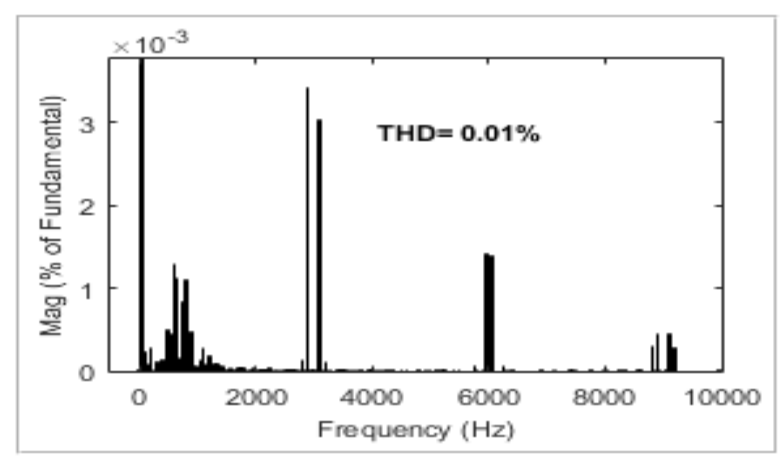

Fig. 22: $\%$ THD of grid fed voltage.

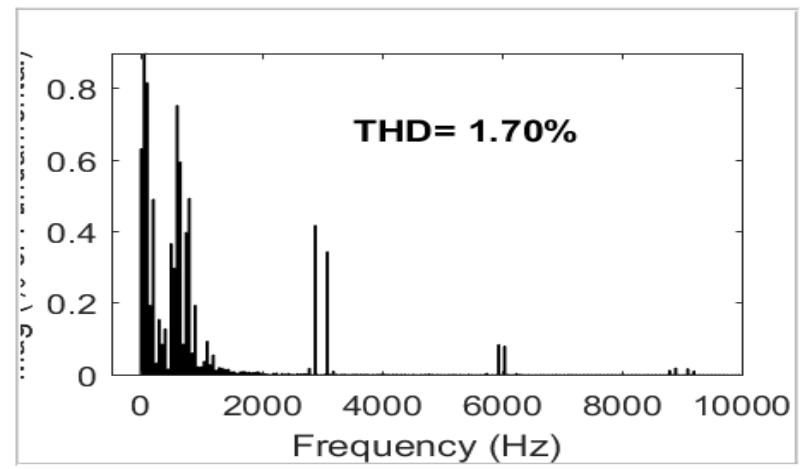

Fig. 23: \% THD of Grid Fed Current. 


\section{Conclusion}

In the present work, Voltage Oriented Control (VOC) based MPPT solution in order to interconnect the solar PV system of $15 \mathrm{~kW}$ with the utility grid is presented and the results are discussed. The $\mathrm{P} \& \mathrm{O}$ algorithm is used for obtaining MPP from the PV array. The simulation results and \% THD values of voltage and current at coupling point show the effectiveness of conventional $\mathrm{P} \& \mathrm{O}$ algorithm with VOC an effective interface is possible with the utility grid. And the results have shown the superiority of VOC method and its high dynamic behavior under variable irradiation conditions. Various PWM algorithms can be employed to reduce \% THD is the further scope of this work.

\section{References}

[1] K. Naoufel, M. Hassan, Z. Malika, B. Youcef, "The MPPT control of PV system by using neural networks based on Newton Raphson method," International renewable and sustainable energy conference, pp.19-24, 2014.

[2] Y. Ting-Chung, C. Tang-Shiuan, "Analysis and simulation of characteristics and maximum power point tracking for photovoltaic systems," International Conference on Power Electronics and Drive Systems, pp. 1339-1344, 2009.

[3] Siwakoti, Y. Prasad, B. B. Chhetri, B. Adhikary, D. Bista, "Micro controller based intelligent DC/DC converter to track maximum power point for solar photovoltaic module," Conference on Innovative Technologies for Efficient and Reliable Electricity Supply, pp. 94-101, 2010

[4] A. Hadi, K. M. Hossein, Y. S. Ahmad, "Stand-alone PV generation system with maximum power point tracking," International Conference on Environment and Electrical Engineering, pp. 549-552, 2010.

[5] N. H. Abdul Rahman, A. M. Omar, "Modeling of a maximum power point tracker for a stand-alone photovoltaic system using MATLAB/Simulink," International Journal of Low- Carbon Technologies, vol. 9, pp.195-201, 2014.

[6] A. Gupta, Y. K. Chauhan, R. K. Pachauri, "A comparative investigation of maximum power point tracking methods for solar PV system," Solar Energy, vol. 136,pp. 236-253, 2016.

[7] M. A. A. M. Zainuri , M. A. M. Radzi, A. C. Soh, N. AbdRahim "Development of adaptive perturb and observe-fuzzy control maximum power point tracking for photovoltaic boost dc-dc converter," IET Renewable Power Generation, vol. 8, pp. 183-194, 2014.

[8] E. M. Ali, A. D. John, Z. Bashar, "Experimental investigation of the incremental conductance maximum power point tracking algorithm at high perturbation rates," IET Renewable Power Generation, vol 10,pp. 133-139, 2016.

[9] M. Kumar, S. R. Kapoor, R. Nagar, A. Verma, "Comparison between IC and fuzzy logic MPPT algorithm based solar PV system using boost converter," International Journal of Advanced Research in Electrical Electronics and Instrumentation Engineering, vol. 4, pp. 4927- 4939, June 2015.

[10] Aredes, M.A., França, B.W. and Aredes, M. "Fuzzy adaptive P\&O control for MPPT of a photovoltaic module," Journal of Power and Energy Engineering, vol. 2, pp. 120-129, 2014. 